\title{
Adequacy of Antimicrobial Empirical Treatment for Sepsis in the Emergency Department of a Large University Hospital
}

\author{
J.M. De Miguel-Yanes*, J. Muñoz-González*, J.A. Andueza-Lillo, J.A. Nuevo-González, \\ V.J. González-Ramallo and B. Moyano-Villaseca
}

\author{
Servicio de Urgencias (Emergency Department). Hospital General Universitario “Gregorio Marañón”. Calle Doctor \\ Esquerdo, 46. 28007. Madrid, Spain
}

\begin{abstract}
Purpose: This retrospective study analyzes the adequacy of the empirical antimicrobial treatment for sepsis at the emergency department according to the results of the microbiological isolations and describes the associations between microbiological variables and mortality. Values for several clinical and microbiological variables were prospectively collected for a total of 101 patients. Cases of inadequate antimicrobial treatment as defined in the text were further studied.

Results: Fifty-two patients had microbiological confirmation of infection (51.4\%), constituting 62 different isolates. Escherichia coli represented half of the cases. One third of the microbiological isolates were not adequately covered by initially chosen treatment, mostly due to microbiological resistances. Having a respiratory source was the only variable associated to inadequate coverage $(\mathrm{p}=0.05)$. Lack of adequate empirical microbiological coverage was not associated with mortality $(\mathrm{p}=0.16)$. In a multivariate test, "respiratory source" $(\mathrm{OR}=46.6[2.2-972 ; 95 \% \mathrm{CI}]$ and "severity" $(\mathrm{OR}=42.5[1.2-$ $1456 ; 95 \% \mathrm{CI}]$ remained significantly associated to mortality.

Conclusions: Lack of empirical coverage for microbiological agents in sepsis is not uncommon. Institutional efforts are needed to improve the empirical use of antimicrobials for sepsis in the Emergency Department.
\end{abstract}

Keywords: Sepsis, Antimicrobial, Empirical treatment, Microbiological isolation, Mortality, Emergency Department.

\section{INTRODUCTION}

Sepsis is a leading cause of in-hospital death [1]. We have previously demonstrated that actions implemented in the Emergency Department (ED) can improve the medical care of patients with sepsis $[2,3]$.

Antimicrobial therapy is one of the milestones of sepsis therapy. A recent study of patients with septic shock showed that the delay in antimicrobial administration after the onset of hypotension was associated with decreasing survival rates [4]. It may seem straightforward that selecting an adequate empirical antibiotic therapy will decrease the mortality rate of patients admitted with sepsis to the ED. Yet, to our knowledge no previous studies have been specifically designed to validate this hypothesis. During the last years, conflicting reports regarding the frequency of inadequate antimicrobial treatment and its effect on the outcome of critically ill patients have been published [5-17].

The main objective of this retrospective study was to analyze the adequacy of empirical coverage for microbiological isolations of patients presenting with sepsis at the ED of

*Address correspondence to these authors at the Servicio de Urgencias. Hospital General Universitario "Gregorio Marañón", Calle Doctor Esquerdo, 46. 28007 Madrid, Spain; Tel: 34915867095;

E-mail: jdemiguel.hgugm@salud.madrid.org

Servicio de Medicina Intensiva. Hospital General Universitario "Gregorio Marañón", Calle Doctor Esquerdo, 46. 28007 Madrid, Spain;

Tel: 34915868615; E-mail: jmunoz.hgugm@ @alud.madrid.org a large teaching Hospital. A secondary objective was to evaluate the association of clinical and microbiological variables with mortality.

\section{MATERIALS AND METHODOLOGY}

\subsection{Study Setting and Population}

We gathered data from patients consecutively coming to our ED along two separate "2-month" periods of time belonging to 2004-2005 and 2007. These two periods were chosen for a comparison among them to evaluate if the 2004 surviving sepsis campaign guidelines had been implemented in this setting [18]. Our institution is a large (1.700 beds) tertiary-care university teaching hospital with a large catchment area of 720.000 people drawn from the south-eastern sector of the city and province of Madrid, Spain.

For clinical research purposes, the definition of "inadequate" antimicrobial treatment of infection included, as described elsewhere, the microbiological documentation of an infection that was not being effectively treated at the time of its identification, the absence of antimicrobial agents directed against a specific class of microorganisms (e.g., for fungal infections) or the administration of an antimicrobial agent to which the microorganism responsible for the infection was resistant [19].

Patients were included whenever physicians from the General Internal Medicine Section of the ED had made the diagnosis of sepsis, severe sepsis, or septic shock for them at any point of their stay in our Department. Furthermore, a 6- 
hour minimum stay at our ED was required; thus, patients with an "earlier than 6-hour" admission to the Intensive Care Unit (ICU) or those who had died shortly after their arrival were excluded. We thought that this requested issue would allow direct comparisons with the results from other studies under the same conditions [20].

Physicians on duty at the observation units were contacted at least 3 times a day for cases report. Additionally, the software used by the Admission Office of our hospital was consulted to identify all those patients admitted with diagnoses related to sepsis that might not have been detected by other means. ICU admissions coming from the ED during that period were also checked. The competent Hospital Authority approved the collection and statistical analysis of the original data. Patients, or a relative in case of inability on behalf of the patient, gave oral consent for data prospective collection.

\subsection{Study Design}

Data were obtained both from written medical charts and from electronic applications for Hematology, Biochemistry and Microbiology Laboratories of the Hospital. They included age, sex, pre-existing conditions predisposing to infection and Acute Physiology and Chronic Health Evaluation (APACHE II) score, calculated with the worst values of the first 6 hours since presentation at the ED [21]; number of failing organs, as defined in previously published guidelines, as well as "severity" following universal definitions of sepsis stages [22, 23] (Tables 1 and 2). Definite source of infection according to final diagnosis and results of cultures from blood, urine and other biological samples were recorded. The pattern of use of antimicrobials was analyzed, especially regarding the appropriateness of the empirical coverage of those microbiological agents lately identified. The final diagnosis, length of hospital stay and the outcome of every patient were surveyed.

\subsection{Data Analysis}

All tests for significance and resulting $\mathrm{P}$ values were 2sided, with a level of significance set at 0.05 . Fisher's exact test and the $\mathrm{X}^{2}$ test were used for categorical variables. For continuous variables, the Kolmogorov-Smirnov test served to identify those variables with a normal distribution, for which the $\mathrm{T}$ test for independent samples was used. The Mann-Whitney U test was used as a nonparametric test for variables that did not follow a normal distribution. A model of backward logistic regression was designed to evaluate those variables significantly associated with mortality. Statistical calculations were done using the SPSS version 15.0 software package (LEAD Technologies, Inc, USA).

\section{RESULTS}

The database comprised 101 cases (data are referred to the total cohort). Mean age was $71.2 \pm 18.4$ years old, with a male to female ratio of $6: 4$. Fifty percent of the patients had no predisposing conditions that could put them at risk to develop sepsis. The average APACHE II score was 17.0 \pm 6.7 . According to the stage of severity, $46 \%$ had sepsis syndrome, $28 \%$ severe sepsis and $26 \%$ septic shock. Sources of infection were urinary tract $(45 \%)$, lung (25\%), abdominal cavity $(17 \%)$ and skin $(13 \%)$.

Blood cultures were drawn in $76 \%$ and the positivity rate was $45 \%$ of this subgroup. Fifty-two patients had a microbiological confirmation of an infection (51.4\% of the whole). In 49 patients, no isolates were identified: in 14 cases no samples at all were sent for culture and in 35 cases, cultures yielded no positive results.

A total of 62 different isolates were identified (Fig. 1). Escherichia coli (E. coli) represented half of the isolates, mostly from urinary or abdominal sources. Simultaneous growth of two agents took place in 10 patients. No single variable was associated to simultaneous growth. In 18 cases the infective agent was identified only in a biological sample other than blood, more commonly in urine $(n=10)$.

Three quarters of the 101 patients initially received one antimicrobial drug and another quarter received two. Thirdgeneration cephalosporins were the most frequently used ones $(32 \%)$, followed by amoxicillin-clavulanate $(16 \%)$ and quinolones $(15 \%)$. Clinical profiles of those cases in which physicians initially chose a combination of antibiotics are

\title{
Table 1. Criteria for Acute Organ Failure
}

\author{
Need for vasoactive drugs \\ Severe hypoxia $(\mathrm{pO} 2 / \mathrm{FiO} 2<200)$, or need for mechanical ventilation \\ Platelet count $<100.000 / \mathrm{mm}^{3}$, or baseline platelet count $/ 2$ \\ Creatinine $>2 \mathrm{mg} / \mathrm{dl}$ or baseline creatinine $\mathrm{x} 2$. Or urine output $<0.5 \mathrm{ml} / \mathrm{kg} / \mathrm{h}$ for more than two hours \\ Bilirrubine $>2 \mathrm{mg} / \mathrm{dl}$ or baseline bilirrubine $\mathrm{x} 2$ \\ Glasgow Coma Score $<15$ points
}

Table 2. Definitions in Sepsis

$$
\begin{aligned}
& \text { Sepsis } \quad \text { SIRS* due to proved or suspected infection. } \\
& \text { Severe sepsis }=\quad \text { sepsis plus acute failure of one or more organs, or impaired perfusion (hyperlactacidaemia) or hypotension (transient o persistent). } \\
& \text { Septic shock }=\text { Hypotension unresponsive to fluid therapy, needing vasoactive drugs. }
\end{aligned}
$$

*SIRS denotes "Systemic Inflammatory Response Syndrome". 


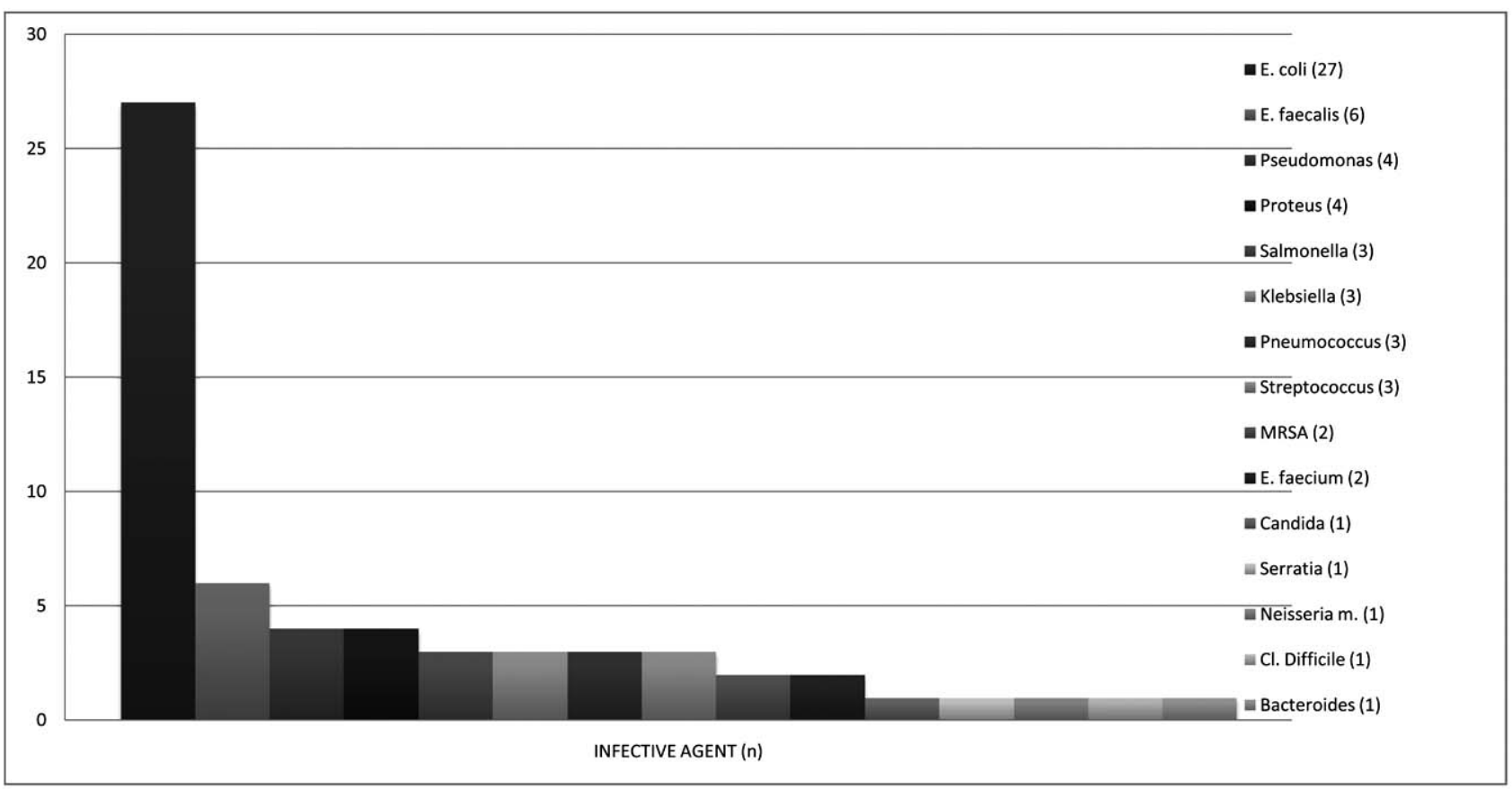

Fig. (1). Definite identification of infective agents.

Table 3. Clinical Profile of Cases Where a Combination of Antimicrobials was Used

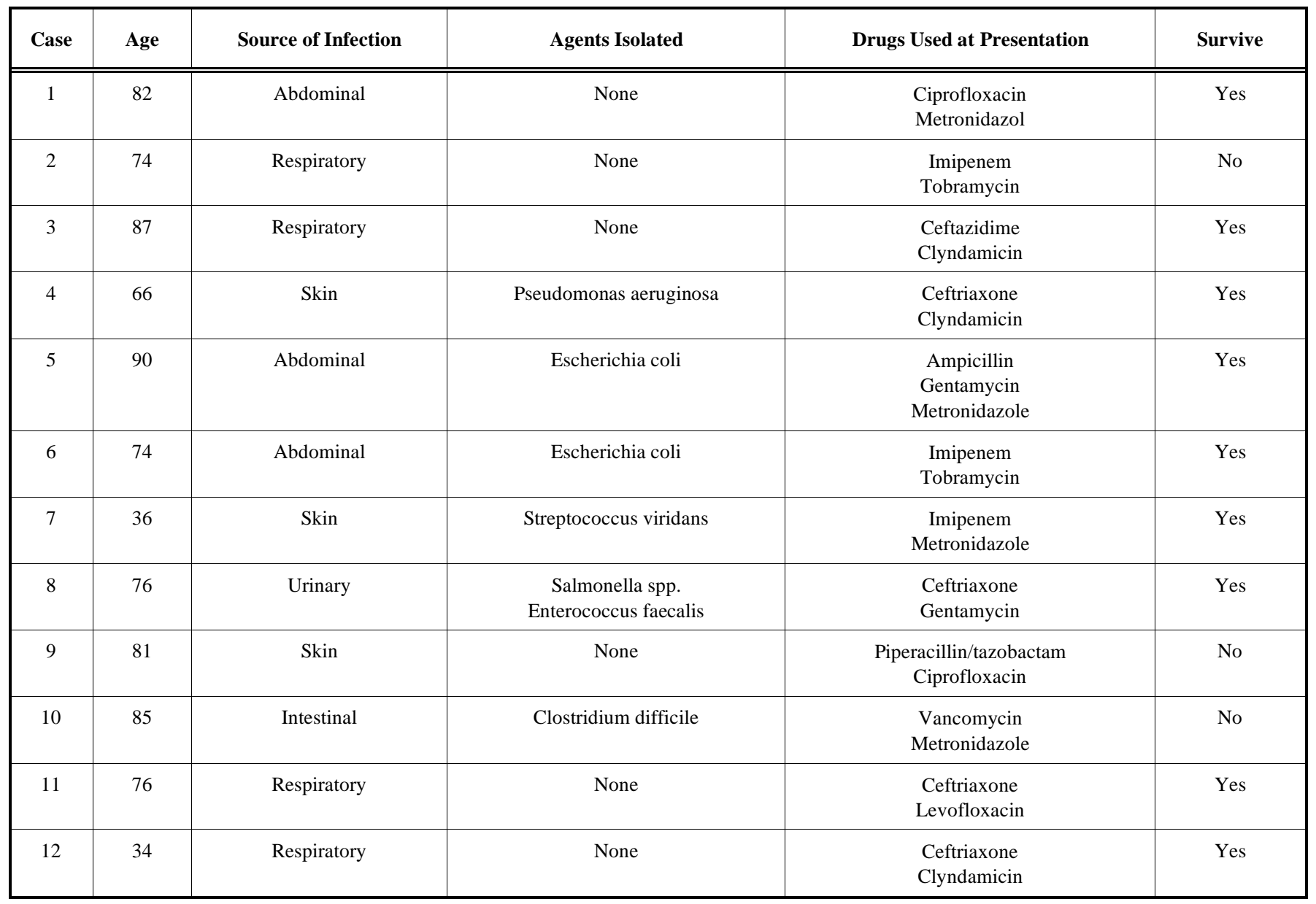


(Table 3). Contd....

\begin{tabular}{|c|c|c|c|c|c|}
\hline Case & Age & Source of Infection & Agents Isolated & Drugs Used at Presentation & Survive \\
\hline 13 & 34 & Respiratory & None & $\begin{array}{l}\text { Vancomycin } \\
\text { Gentamycin }\end{array}$ & Yes \\
\hline 14 & 66 & Respiratory & None & $\begin{array}{c}\text { Aztreonam } \\
\text { Azithromycin }\end{array}$ & No \\
\hline 15 & 94 & Skin & Pseudomonas aeruginosa & $\begin{array}{l}\text { Ceftriaxone } \\
\text { Clyndamicin }\end{array}$ & No \\
\hline 16 & 92 & Respiratory & None & $\begin{array}{l}\text { Ceftriaxone } \\
\text { Levofloxacin }\end{array}$ & Yes \\
\hline 17 & 42 & Respiratory & Streptococcus pneumoniae & $\begin{array}{l}\text { Ceftriaxone } \\
\text { Levofloxacin }\end{array}$ & Yes \\
\hline 18 & 28 & Skin & Streptococcus viridans & $\begin{array}{l}\text { Cloxacillin } \\
\text { Amikacin }\end{array}$ & Yes \\
\hline 19 & 75 & Skin & $\begin{array}{l}\text { Escherichia coli } \\
\text { Proteus mirabilis }\end{array}$ & $\begin{array}{c}\text { Ceftriaxone } \\
\text { Metronidazole }\end{array}$ & Yes \\
\hline 20 & 81 & Urinary & None & $\begin{array}{c}\text { Imipenem } \\
\text { Vancomycin }\end{array}$ & No \\
\hline 21 & 88 & Urinary & Escherichia coli & $\begin{array}{c}\text { Amoxicillin/clavulanate } \\
\text { Gentamycin }\end{array}$ & Yes \\
\hline 22 & 98 & Abdominal & Klebsiella pneumoniae & $\begin{array}{l}\text { Ciprofloxacin } \\
\text { Metronidazole }\end{array}$ & Yes \\
\hline
\end{tabular}

Table 4. Patients with Infections without a Correct Empirical Antibiotic Coverage at Presentation

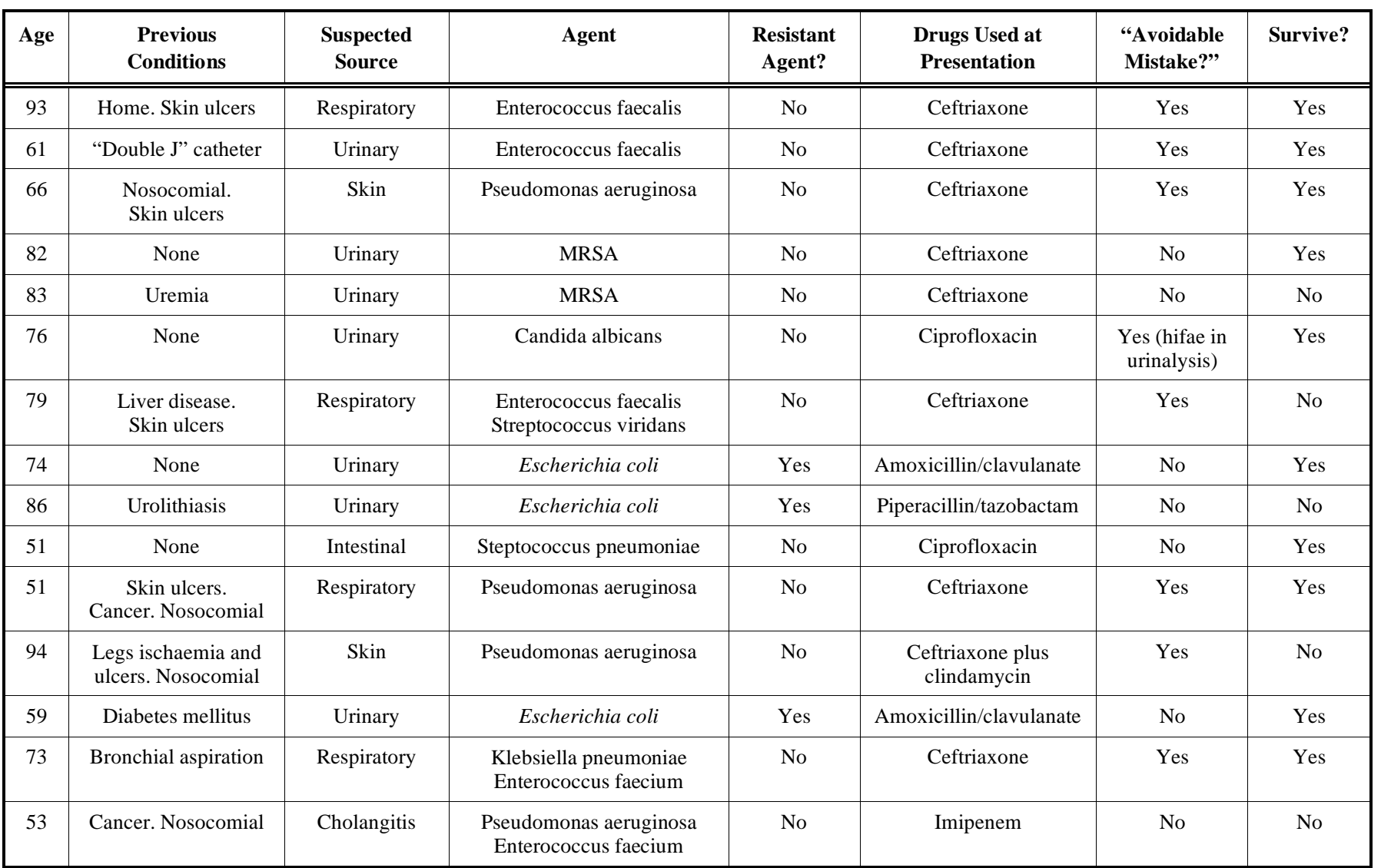

MRSA: Methicillin-resistant Staphylococcus aureus.

"Avoidable mistake" denotes cases where previous clinical background or suspected source should have prompted the use of a more aggressive pattern of antimicrobials. However, e.g., unexpected resistances, routine coverage of MRSA pneumonia in a non-institutionalized patient or a mistake in identifying source of infection were not classified as "preventable". 
shown in Table 3. No variables were statistically associated with having chosen a combination of antibiotics.

According to the antibiotic susceptibilities, $30 \%$ of the isolated agents, corresponding to 15 patients, were not appropriately covered at presentation (Table 4). The rate of adequacy for E. coli was $89 \%$ (Fig. 2). Leaving microorganisms untreated due to having used a wrong antibiotic coverage was more frequent in cases of respiratory infections $(\mathrm{p}=0.05)$, but no other variable could be identified in this respect.

The variables "severity" $(\mathrm{p}=0.004)$, "isolation of two or more agents" $(p=0.02)$ and "respiratory source" $(p=0.03)$ were associated with mortality in the univariate test, though "lack of empirical coverage" was not $(\mathrm{p}=0.16)$. In a multivariate model, "respiratory source" $(\mathrm{OR}=46.6$ [2.2-972; $95 \% \mathrm{CI}]$ and "severity" $(\mathrm{OR}=42.5$ [1.2-1456; 95\%CI] remained significantly associated with mortality.

\section{DISCUSSION}

Recently, a great emphasis has been put in medical literature on the hemodynamic aspects of sepsis in the ED [20]. Furthermore, the time wasted until the administration of the first dose of an antibiotic has been highlighted as a paramount factor for the survival of patients with septic shock [4]. To our opinion, less importance has been given to the possible benefit of an accurate initial empirical choice of antibiotics according to the suspected source of infection, to pre-existing medical conditions and to the local susceptibilities to antimicrobials.

Remarkably, up to $30 \%$ of our isolates were not properly covered with the antibiotics initially used. Combining antibiotics did not prove to be effective either. Yet, had our physicians widened the antibiotic coverage for those patients with skin ulcers and prior admissions to the hospital, then Enterococcus faecalis and Pseudomonas aeruginosa would have initially been more appropriately treated, irrespectively of the source of the infection. Also, the possibility of Enterococcus faecalis infection in patients with previous procedures on the urinary tract and of Gram-negative agents in patients with suspected bronchial aspiration might have been anticipated.

Previous trials have shown that up to $19 \%$ of the patients with sepsis receive inadequate empirical coverage in clinical trial optimal settings [24-26]. The rate is even higher in other single-centre, observational studies of aggressive infections [27]. It may be argued that the antimicrobial use policy at any hospital should follow the knowledge of local antibiotic patterns of use and resistances. However, the complexity of the drug selection process can bring confusion for clinicians in the ED: both the possibility of an infection caused by drug-resistant pathogens and the wide range of antimicrobial agents available may hamper the choice of an effective antimicrobial regimen. The clinical repercussion of this fact is that the mortality rate of a bacteraemia could be reduced with an adequate use of antibiotics [28-31]. Kollef et al. reported that the inadequate empirical antibiotic therapy was an independent predictor of the hospital mortality rate in a group of critically ill patients with either communityacquired or ICU-acquired infections [5], yet other studies failed to support this conclusion [32].

In our study, data were retrospectively collected from two different periods of time, and cases with no microbiological isolation were not evaluated. As a result, a low number of cases were suitable for analysis. Notwithstanding these caveats, our study highlights the high rate of failure in the indication of antibiotic empirical treatment in the ED. Aspects relative to the systemic impact of the disease and the

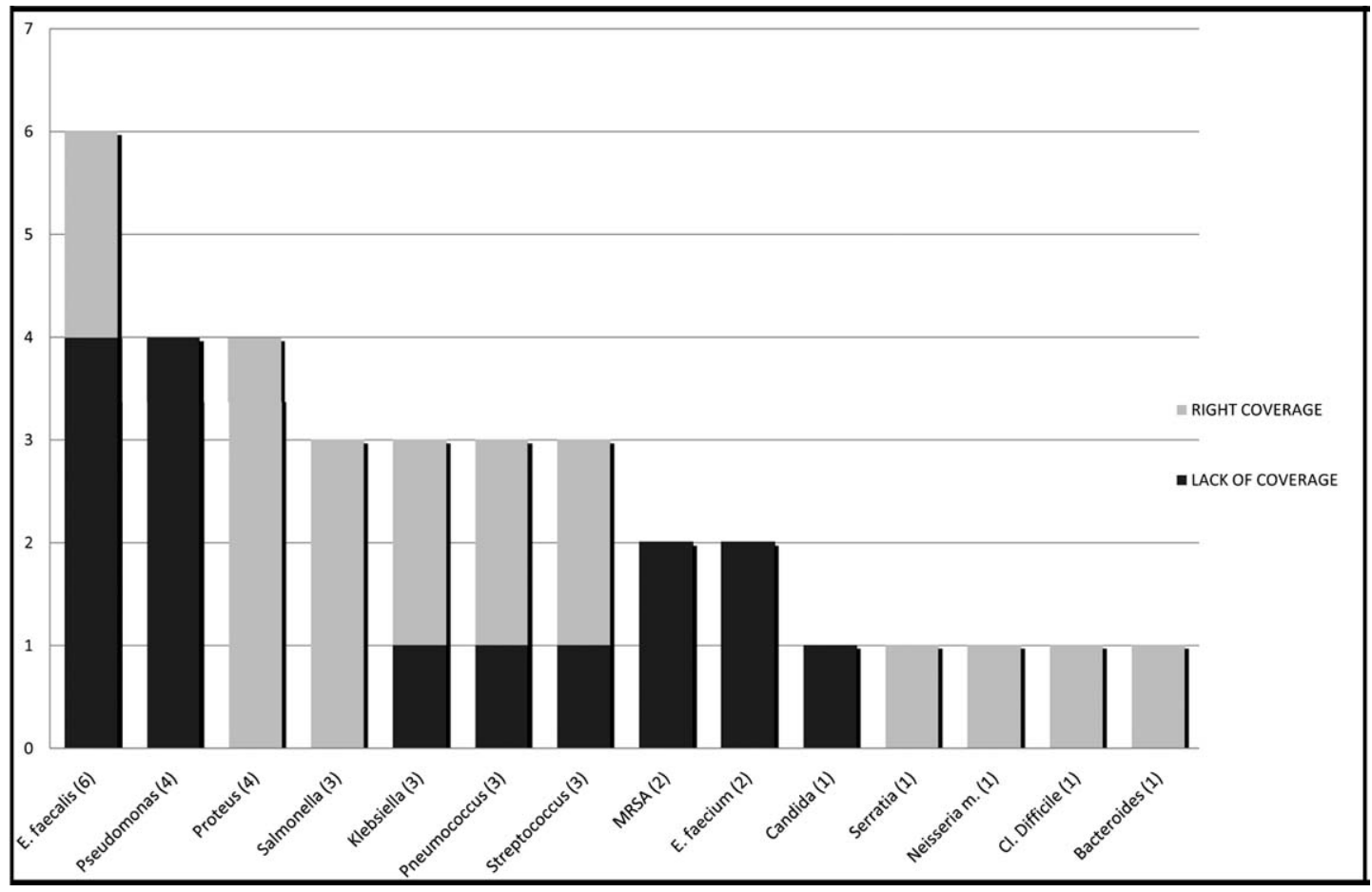

Fig. (2). Number of cases (n) with lack of antimicrobial coverage (light-colored) as opposed to correct coverage (dark-colored) for isolated agents. 
previous conditions of the patient also appear as powerful factors with effect on survival.

Even more interesting can be the finding that, in our study, barely half of the failures of prescription could have been prevented with protocols: no protocol would have helped adequately treat the other half. Choosing a wider antibiotic coverage in the most seriously ill patients could decrease mortality, but it might as well have a deleterious influence on later emergences of antimicrobial resistances.

\section{CONCLUSION}

Many questions regarding the impact of infection caused by antimicrobial-resistant pathogens on the mortality of patients with sepsis still need to be clarified. This study highlights the importance of identifying pitfalls in the empirical use of antimicrobials; otherwise, the remaining "bundle" measures included in universal guidelines may lose effectiveness in achieving lower mortality rates for patients with sepsis.

\section{ABBREVIATIONS \\ $\mathrm{ED} \quad=$ Emergency Department \\ ICU = Intensive Care Unit \\ E. coli = Escherichia coli}

\section{CONFLICT OF INTEREST}

This paper was conducted without institutional funding or financial support from the pharmaceutical industry. No other potential conflict of interest is disclosed.

\section{REFERENCES}

[1] Angus DC, Linde-Zwirble WT, Lidicker J, Clermont G, Carcillo J, Pinsky MR. Epidemiology of severe sepsis in the United States: analysis of incidence, outcome, and associated costs of care. Crit Care Med 2001; 29(7): 1303-10.

[2] De Miguel-Yanes JM, Andueza-Lillo JA, González-Ramallo VJ, Pastor L, Muñoz J. Failure to implement evidence-based clinical guidelines for sepsis at the ED. Am J Emerg Med 2006; 24(5): 5539 .

[3] De Miguel-Yanes JM, Muñoz-González J, Andueza-Lillo JA, Moyano-Villaseca B, González-Ramallo VJ, Bustamante-Fermosel A. Implementation of a bundle of actions to improve adherence to Surviving Sepsis Campaign guidelines at the ED. Am J Emerg Med 2008; (in press).

[4] Kumar A, Roberts D, Wood KE, et al. Duration of hypotension before initiation of effective antimicrobial therapy is the critical determinant of survival in human septic shock. Crit Care Med 2006; 34(6): 1589-96.

[5] Kollef MH, Sherman G, Ward S, Fraser VJ. Inadequate antimicrobial treatment of infections: a risk factor for hospital mortality among critically ill patients. Chest 1999; 115(2): 462-74.

[6] Ibrahim EH, Sherman G, Ward S, Fraser VJ, Kollef MH. The influence of inadequate antimicrobial treatment of bloodstream infections on patient outcomes in the ICU setting. Chest 2000; 118(1): 146-55.

[7] Bates DW, Pruess KE, Lee TH. How bad are bacteraemia and sepsis? Outcomes in a cohort with suspected bacteraemia. Arch Intern Med 1995; 155(6): 593-8.

[8] Pittet D, Thiévent B, Wenzel RP, Li N, Auckenthaler R, Suter PM. Bedside prediction of mortality from bacteraemic sepsis: a dynamic analysis of ICU patients. Am J Respir Crit Care Med 1996; 153(2): 684-93.

[9] Heyland DK, Cook DJ, Griffith L, Keenan SP, Brun-Buisson C. The attributable morbidity and mortality of ventilator-associated pneumonia in the critically-ill patient. Am J Respir Crit Care Med 1999; 159(4): 1249-56.

[10] Zaragoza R, Artero A, Camarena JJ, Sancho S, González R, Nogueira JM. The influence of inadequate empirical antimicrobial treatment on patients with bloodstream infections in an Intensive Care Unit. Clin Microbiol Infect 2003; 9(5): 412-8.

[11] Dupont H, Montravers P, Gauzit R, Veber B, Pouriat JL, Martin C. Outcome of postoperative pneumonia in the EOLE study. Intensive Care Med 2003; 29(2): 179-88.

[12] Harbarth S, Ferriere K, Hugonnet S, Ricou B, Suter P, Pittet D. Epidemiology and prognostic determinants of bloodstream infections in surgical intensive care. Arch Surg 2002; 137(12): 1353-59.

[13] Alvarez-Lerma F. Modification of empiric antibiotic treatment in patients with pneumonia acquired in the intensive care unit. Intensive Care Med 1996; 22: 387-94.

[14] Leibovici L, Shraga I, Drucker M, Konigsberger H, Samra Z, Pitlik $\mathrm{SD}$. The benefit of appropriate empirical antibiotic treatment in patients with bloodstream infections. J Intern Med 1998; 244(5): 37986.

[15] Fagon JY, Chastre J. Management of suspected ventilatorassociated pneumonia. Ann Intern Med 2000; 133(12): 1009-14.

[16] Toubes E, Singh K, Yin D, et al. Risk factors for antibioticresistant infection and treatment outcomes among hospitalized patients transferred from long-term care facilities: does antimicrobial choice make a difference? Clin Infect Dis 2003; 36(6): 724-30.

[17] Leone M, Bourgoin A, Cambon S, Dubuc M, Albanèse J, Martin C. Empirical antimicrobial therapy of septic shock patients: adequacy and impact on the outcome. Crit Care Med 2003; 31(2): 462-7.

[18] Dellinger RP, Carlet JM, Masur H, et al. Surviving sepsis campaign guidelines for management of severe sepsis and septic shock. Crit Care Med 2004; 32(3): 858-73.

[19] Kollef MH. Inadequate antimicrobial treatment: an important determinant of outcome for hospitalized patients. Clin Infect Dis 2000; 31(Suppl 4): S131-8.

[20] Rivers E, Nguyen B, Havstad S, et al. Early goal-directed therapy in the treatment of severe sepsis and septic shock. N Engl J Med 2001; 345(19): 1368-77.

[21] Knaus WA, Draper EA, Wagner DP, Zimmerman JE. APACHE II: a severity of disease classification system. Crit Care Med 1985; 13: 818-29.

[22] Bone RC. Let's agree on terminology: definitions of sepsis. Crit Care Med 1991; 19: 973-6.

[23] Levy MM, Fink MP, Marshall JC, et al. International sepsis definitions conference. $2001 \mathrm{SCCM} / \mathrm{ESICM} / \mathrm{ACCP} / \mathrm{ATS} / \mathrm{SIS}$ International Sepsis Definitions Conference. Intensive Care Med 2003; 29(4): 530-8.

[24] Abraham E, Wunderink R, Silverman H, et al. Efficacy and safety of monoclonal antibody to human tumour necrosis factor alpha in patients with sepsis syndrome. A randomized, controlled, doubleblind, multicenter clinical trial. JAMA 1995; 273(12): 934-41.

[25] Opal SM, Fisher CJ Jr, Dhainaut JF, et al. Confirmatory interleukin-1 receptor antagonist trial in severe sepsis: a phase III, randomized, double-blind, placebo-controlled, multicenter trial. Crit Care Med 1997; 25(7): 1115-24.

[26] Bernard GR, Wheeler AP, Russell JA, et al. The effects of ibuprofen on the physiology and survival of patients with sepsis. N Engl J Med 1997; 336(13): 912-8.

[27] Bodí M, Rodríguez A, Solé-Violán J, et al. Community-acquired pneumonia intensive care units (CAPUCI) study investigators. Antibiotic prescription for community-acquired pneumonia in the intensive care unit: impact of adherence to Infectious Diseases Society of America guidelines on survival. Clin Infect Dis 2005; 41(12): 1709-16.

[28] Cisneros JM, Reyes MJ, Pachón J, et al. Bacteremia due to Acinetobacter baumannii: Epidemiology, clinical findings and prognostic features. Clin Infect Dis 1996; 22(6): 1026-32.

[29] Gatell JM, Trilla A, Latorre X, et al. Nosocomial bacteraemia in a large Spanish teaching hospital: Analysis of factor influencing prognosis. Rev Infect Dis 1988; 10(1): 203-10. 
[30] Pedersen G, Schonheyder HC, Sorensen HT. Antibiotic therapy and outcome of monomicrobial Gram-negative bacteremia: A 3year population-based study. Scand J Infect Dis 1997; 29: 601-6.

[31] Uzun O, Akalin HE, Hayran M, Unal S. Factors influencing prognosis in bacteraemia due to Gram-negative organisms: evaluation of 448 episodes in a Turkish university hospital. Clin Infect Dis 1992; 15(5): 866-73.

[32] Rello J, Ricart M, Mirelis B, et al. Nosocomial bacteraemia in a medical-surgical intensive care unit: epidemiologic characteristics and factors influencing mortality in 111 episodes. Intensive Care Med 1994; 20(2): 94-8.

Received: April 26, 2009

Revised: June 11, 2009

Accepted: June 11, 2009

(C) De Miguel-Yanes et al.; Licensee Bentham Open.

This is an open access article licensed under the terms of the Creative Commons Attribution Non-Commercial License (http://creativecommons.org/licenses/by-nc/3.0/) which permits unrestricted, non-commercial use, distribution and reproduction in any medium, provided the work is properly cited. 